ARTICLE

Received 20 Jan 2017 | Accepted 24 May 2017 | Published 4 Jul 2017

DOl: 10.1057 /palcomms.2017.65

\title{
The "competent child" in times of crisis: a synthesis of Foucauldian with critical discourse analysis in Greek pre-school curricula
}

\author{
Yannis Pechtelidis ${ }^{1}$ and Anastasia G. Stamou ${ }^{2}$
}

\begin{abstract}
Late modern children usually have school experiences from a very young age. Therefore, official educational discourses have the potential to shape their everyday life and subjectivity. The objective of this article is to explore the forms of knowledge that were produced around early childhood and schooling by the two most recent curricula of the Greek pre-school educational system in an era of crisis. In this framework, a discourse analytical approach is proposed which combines Foucauldian with critical discourse analysis. From the analysis, it appears that both curricula actively engage in the discursive struggle for hegemony in society, producing a specific understanding of childhood and schooling. In particular, according to the analysis, both curricula echo a neo-liberal discourse, which could exert a specific ideological power upon young children's subjectivity. However, it was found that the most recent curriculum is even more focused on the neo-liberal ideological project. This conceptual shift could be understood in the current context of the hegemony of the neoliberal ideology in the social field. Moreover, it was found that both curricula contain several child-oriented elements, crafting the image of "the competent child". However, these elements could probably function as a subtle instrument for further achieving the aims of the neo-liberal hegemonic discourse for antagonism and entrepreneurship. As children do not passively receive the content addressed to them, future research on the relationship between representations and subjective experiences is deemed necessary.
\end{abstract}

\footnotetext{
${ }^{1}$ Department of Early Childhood Education, University of Thessaly, Volos, Greece ${ }^{2}$ Department of Early Childhood Education, University of Western Macedonia, Florina, Greece
} 


\section{Introduction}

onsidering that children in late modernity tend to have educational experiences from a very young age, social control and regulation start to be exerted early in people's lives. From this perspective, understanding the power that educational discourses, such as curricula, might have is an important issue, because they contribute to the shaping of children's everyday lives and experiences. Curricula are forms of representation and knowledge of a specific subject such as children's nature and schooling. Such knowledge and understanding affects social practices and has real consequences for the subjects involved (Olson et al., 2014). Hence, curricula are a vital part of educational policy, contributing to the welfare of the child. Considering that the welfare of child is not purely a scientific or technical issue, but mostly a political one (Parton, 2014), we believe that a discourse analysis of curricula can bring out their socio-political aspects.

In the present study, we aim to analyse the two most recent (2003 and 2011) Greek pre-school education curricula. We view both curricula as specific discourses producing particular meanings about schooling and young children's role, which are in dialogue with a wider nexus of universal discourses about childhood and education. Adopting a comparative perspective, we seek to detect any conceptual differences between the two texts. To this end, we explore the representations about the nature of early childhood and education that emerge from the two curricula and evaluate their role in the (dis)empowerment of children's status, by proposing a synthesis of two well-known strands in discourse theory, namely Foucauldian discourse analysis and critical discourse analysis. Our discourse analytical approach is theoretically informed by Governmentality Studies (Foucault, 1984; Dean, 2009; Silcock et al., 2016) and the New Sociology of Childhood (James and Prout, 1990).

\section{Governance and images of childhood}

In discourse theory, subjectivity is considered to be produced through various forms of knowledge and specific power relations (Foucault, 1984). Curricula are specific symbolic articulations between power and knowledge, controlling the way we understand childhood. In this sense, we claim that the curriculum is a bio-power technology exerted upon children's bodies. Bio-power literally means having power over bodies. It is a technology of power for governing people, and it is closely related to biopolitics. A typical feature of bio-politics is the prevalence of governance over government. Governance takes the form of guidance towards specific socio-political and financial goals. It consists of technologies, which are not applied to the social body, but to individuals, through the guidance of the subjective body. In other words, bio-power is a technology of governance that aims directly at the subjects' body and mind (Dean, 2009). By this process, individuals are invited to change through practices of "improvement" in the name of individual happiness or collective health. The bio-power technologies of governmentality make social actors capable of monitoring and controlling their own behavior (Haldar and Engebretsen, 2014).

To grasp the meanings and the values of the bio-power technology of the current curricula, we need to situate them in the context of the recent financial and political crisis in Greece. In specific, the liberal political establishment has been transformed into a technocratic and authoritarian regime under the global rule of neo-liberalism. Under the hegemony of financial capital, a technocratic "pragmatism" coalesces with the authoritarian politics of the state and a bio-power is exercised directly on the "body" of society. The surpass of the traditional divide between the left and the right in the political system, the treatment of political and social issues solely as technical questions, and the increasing "rule of experts" in governance are the central characteristics of post-democracy, in which the most significant decisions about economic and other policies are no longer subject to extensive political debate and conflict (Crouch, 2004; Mouffe, 2005: 29).

Under this perspective, the bio-power technology of the current curricula mainly targets children's behavior and practices. This could relate to the generalised interest of modern states to regulate and control the entire population (Rose, 1989). In fact, Rose (1989) has argued that children are the main object of control of the society. Thus, we claim that curricula intervene and regulate children's bodies through processed and subtle ways of control. Children's body is simultaneously the target and the instrument of disciplinary power in the curricula, which transmit beneficial information and knowledge to children into exactly exploit all these information, knowledge and skills in the near future. In this way, the bio-political system produces subjects who conform to the choices they are given to by the system. Therefore, the effectiveness of the socio-economic system depends on the bio-political regulation of subjectivity and desire (Dean, 2009).

Against this backdrop, the way childhood is understood nowadays is the result of a complex series of overlapping material and discursive practices, which closely relate to the governance of children's bodies. Specifically, modernity is connected to a specific conceptualization of childhood, according to which the "child" is represented as the "other" and is contrasted to "adults" (Jenks, 1996). In particular, children are represented as connected to nature, irrationalism, dependence, immaturity, play, and the private sphere, whereas adults are seen as related to civilisation, rationalism, independence, work, and the public sphere. It is worth mentioning that this ideal encompasses contradictory ideas about children. On the one hand, they are seen as innocent, dependent, pure, incompetent, and unable to work. On the other hand, they are considered inherently fierce, cruel, and threatening, putting themselves and society in danger. It is worth noting that, although these modern discourses about childhood have been mainly produced within the Western socio-cultural context, they exert their hegemonic power on a worldwide scale, as a result of current globalisation processes. In any case, they seem to have still currency within the Greek society (Avgitidou and Stamou, 2013).

We could claim that these contradictory discourses about childhood are linked to the generalised interest of modern states to regulate and manipulate the entire population (Rose, 1989). "Modern" disciplinary power demands social consensus about the legitimacy of its preventive and regulative practices upon children's bodies through its polished and subtle ways of surveillance and control (Jenks, 1996). Hence, children are the typical object of control and surveillance of the adult society (Rose, 1989). Yet, in late modernity, a different conceptualisation of childhood is developed, as the sustainability of the current hegemonic neo-liberal regimes presupposes a different socialisation process of children. Specifically, children's welfare is closely connected with autonomy, and therefore the child is perceived as an active partner in the socialisation process (Smith, 2012). However, the competent, autonomous and reflective child represents a relatively new form of governance, which emphasises children's views, and their right of choice and participation in the decision making about matters that concern them. Although the image of the competent child creates a new potential for childhood, it facilitates, at the same time, new forms of regulation and control, which shift responsibility from adults to children. 


\section{The discourse analytical approach proposed}

We employ the concept of "discourse" as a methodological tool to illuminate the relation between a specific pedagogical knowledge about childhood and schooling and forms of social control imposed upon children according to this particular knowledge. Discourses are symbolic systems and social orders, and discourse analysis explores their historical, social and political formation and "function" (Laclau and Mouffe, 1985). They are not simply texts, but they are relatively well-bounded fields of social knowledge about what is possible to say or do at a given moment (Foucault, 2008: 23-43). Regarding children, we could argue that the pre-school educational discourses under study are social practices causing material consequences to the status of children, since they might strengthen or weaken children's social position within society. In light of this, our aim is to trace these discursive practices, and to bring the power relations and domination they entail into surface.

To this end, we proceed to a discourse analysis of the two most recent curricula of Greek pre-school education, by proposing a synthesis of critical discourse analysis (henceforth CDA) and Foucauldian discourse analysis (henceforth FDA). Through this synthesis, we aim to better combine a close linguistic analysis of texts, which is a characteristic of $\mathrm{CDA}$, with a social orientation to discourse, which characterizes FDA, and thus to integrate analysis at the micro-level of social action with analysis at the macro-level of social structure. Although Foucauldian thinking has been recognised as an important influence for CDA, particularly with respect to the concept of discourse and subjectivity (for example, Wodak, 2001), few attempts have been made to bring to dialogue these two discourse analytical strands (for example, Liao and Markula, 2009).

We would like to put the proposed synthesis under a more general "multiperspectival" research agenda (Jørgensen and Phillips, 2002). In particular, Jørgensen and Phillips distinguish multiperspectivalism from eclecticism, by acknowledging the fact that each approach (as in our case, CDA and FDA) constitutes a methodological whole, that is, in their terms, a "complete package" (Jørgensen and Phillips, 2002: 4). Then, it is possible (and legitimate) to create one's own "package" by combining elements from different approaches together, on the condition that the kind of (local) knowledge supplied by each approach is identified, as well as the philosophical and theoretical differences and similarities among the approaches to be synthesised are taken into consideration.

In our case, since both approaches have as a starting point the epistemology of social constructionism, we argue that such a synthesis is possible and fruitful, since it can strengthen our analysis of educational discourses by seeking to better integrate textual with social analysis. Specifically, as a linguisticallyoriented discourse analysis, CDA has developed a great range of analytical tools for a close textual analysis. Yet, it has been criticised for giving an over-emphasis to texts (the so-called micro-level of text, following Fairclough's (1992) threedimensional model for the analysis of discursive events) to the detriment of social structure (the so-called macro-level of social practice, following Fairclough), while it has been also accused for failing to incorporate a solid social theory for the latter, resorting to "a kind of ad hoc bricolage which takes from theory whatever concept comes usefully to hand" (Widdowson, 1998: 137).

On the other hand, FDA makes an important contribution to the formation of discourses (the so-called meso-level of discursive practice, following Fairclough) and to a social theory of discourses, such as the relationship of a discourse with power/ knowledge and the discursive constitution of subjects (the socalled macro-level of social practice, following Fairclough). However, it is a more "abstract" approach, failing to develop a concrete toolkit for textual analysis, except for the formulation of "rules of formation" and "conditions of possibility" of discourses (Fairclough, 1992). This means that FDA excludes from consideration actual instances of discourse and the linguistic mechanisms which instantiate particular discourses in texts. In this way, FDA tends to arrive at conclusions about practice without directly analysing texts, namely, it belongs to "nontextually-oriented discourse analyses" (Fairclough, 1992).

Under this scope, we attempt to combine analytical tools drawn upon from CDA, for addressing micro-level textual analysis, with the framework for the formation of discourses as described by Foucault in his "Archeology of Knowledge" (2008), for addressing meso-level discursive practice. Dealing particularly with discourses of childhood, the meso-level analysis is also informed by the New Sociology of Childhood (see Section 2 above). On the other hand, the macro-level social practice resides in the Foucauldian concepts of governance and bio-power, as also sketched in Section 2. In this way, in our synthesis, we creatively combine concepts and tools from both FDA and CDA, forming a new "package", according to Jørgensen's and Phillips's (2002) proposed multiperspectival research agenda (see Fig. 1).

First, the FDA framework is presented, followed by the CDA analytical tools employed in the present study. Drawing on Foucault (2008), discourses are viewed as conceptual schemes about what is possible to say or do at a given moment. Considering childhood, we could claim that the discourses of the study (the curricula) are social practices causing material consequences to the status of young children; they either strengthen or weaken children's social position within the social structure. In this sense, our aim is to explore these practices and the subject positions which follow from these, as well as to consider the social consequences of the representations of "childhood" that they produce.

Specifically, Foucault argued that every discourse contains four interrelated fundamental rules, the "rules of formation" (Foucault, 2008: 34-43). Our analysis, in the next section, is structured along these four rules, following Doxiadis's (2011: 179-188) suggestion to use these rules as analytical resources to approach particular discourses:

The formation of objects. Here, we will examine the relationship between the discourses of the study and the world. We will trace the objects or the elements of real life that are represented in the specific curricula of the analysis.

The formation of enunciative modalities. Under this rule, we will describe who speaks, and from which social position and

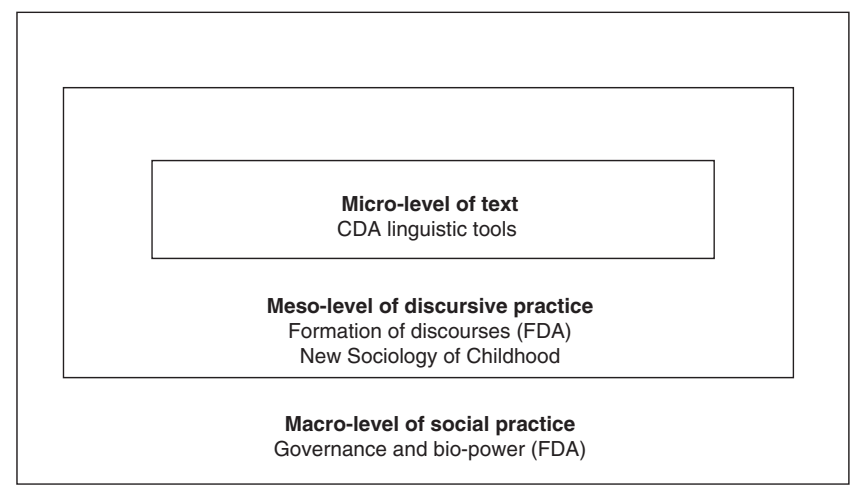

Figure 1 | The proposed synthetic FDA-CDA framework adapted to Fairclough's (1992) three-dimensional model for the analysis of discursive events. 
perspective. In doing so, we can understand children's status in the discursive domain of the curricula. Moreover, we will consider the external or material conditions of discourses production. In this way, discourses are located within the broader sociopolitical and historical context.

The formation of concepts. In this part of analysis, we will discuss the central concepts around which knowledge is produced in both curricula. Particularly, we want to examine the relation of the discourses of the study with scientific and political discourses to show how central concepts are represented.

The formation of strategies. Finally, we will describe the discursive strategies around certain controversial themes, which are related to the central concept(s) of the discourses of the study.

The aforementioned formation rules (Foucault, 2008: 44-85) will be enriched by the analytical toolkit provided by CDA. Far from constituting a single and homogeneous discourse analytical approach, $\mathrm{CDA}$ is a theoretical nexus encompassing different strands. In particular, we draw upon the socio-cultural strand of Fairclough (1992), which heavily exploits micro-linguistic tools from the Systemic Functional Grammar of Halliday (1994). Hallidayan linguistics sees language as a network of options amongst which speakers make selections according to social circumstances, assuming that choices of forms construct different versions of the world. In particular, for the present analysis, we will focus on some well-established linguistic tools which have proven important for CDA research. It is beyond the scope of the present study to provide a quantitative and exhaustive linguistic analysis of the Greek pre-school curricula. Instead, we would like to make some qualitative observations on the two curricula based on the selected linguistic tools.

Specifically, our analysis will focus on the lexical choices adopted in the two curricula. CDA challenges a static dictionarybased view of vocabulary and reconceptualises it as a plane of ideological expression. The ideological investment of vocabulary occurs in two ways. First, it is manifested in the selection of words used to refer to the world, namely to the wording or "lexicalization" process of meaning (Fairclough, 1992). Hence, there are always multiple or alternative wordings/ lexicalizations of experience, which shape different or even contrasting constructions of the world (for example, the wording of a social phenomenon as "immigration" or as "mobility"). Second, the ideological role of vocabulary is expressed through word meaning, that is, what meaning is given to a word. Again, this is not given, but rather socially variable and contested, and often even an object of ideological conflict (for example, about what meaning is given to the word "freedom" in the context of a neo-liberal discourse).

Furthermore, we will look at some "transitivity" patterns of the curricula (Halliday, 1994). As transitivity reveals how causality and responsibility of actions are linguistically constructed, is an analytical area that has developed extensively within CDA, because it is "at the heart of the expression of ideology" (Trew, 1979: 123). Particularly, transitivity involves the interpretation of experience in terms of "processes" and "participants". Moreover, the type of processes used for representing the world must be determined. Another crucial element of transitivity is to consider which participant has an active role in the process (that is, the "agent") and which participant has a passive role in the process (that is, the "medium"). Following the syntactic selections made in a text (for example, a process expressed through active or passive syntax, through a verb or a nominalisation), it is possible to foreground or background an agent, by positioning each clause on a "causality scale" (Stamou, 2001). This has been the object of many CDA studies (for example, Trew, 1979; Van Dijk, 1991) examining media accounts of important events. In our case, the construction of childhood and teacher's role will be particularly addressed through transitivity analysis.

On the other hand, "person deixis" (Lyons, 1979) is in the realm of "interpersonal meanings" (Halliday, 1994) and involves any references made about the speaker and/or hearer and the social relationship established between them (for example, intimate, distant), through particular selections in the personal pronominal system. Thus, through person deixis, we will define who speaks, and from which social position and perspective (for example, formal or informal style) (the internal conditions of enunciative modalities in Foucauldian terms).

Finally, we will consider how reality in the two curricula is naturalised, through "modality" and "presuppositions". Modality concerns the extent to which a speaker signals to commit to or distance himself from an utterance (Fairclough, 1992). In other words, it signals degrees of truth (epistemic modality) or degrees of obligation (deontic modality) (Lyons, 1977). Modality in grammar is traditionally associated with modal verbs (for example, "may", "must") and adjectives/ adverbs ("possible/ly", "necessary/ily"), although there is a wide range of other linguistic (for example, tense, hedges) and paralinguistic (for example, intonation patterns)/ extralinguistic (for example, bodily movements) possibilities (for an account of modality in Greek language, see, for example, Tsangalidis, 2001; Iakovou, 2003; Koutsantoni, 2005). As Fairclough (1992) particularly notes, modality is closely knitted to issues of power, as what can be claimed as "truth" or "obligation" depends on power relations. Categorical statements, that is, statements with the absence of any modality (Halliday, 1994) naturalise the world, since they represent it as non-negotiable. On the other hand, presuppositions concern propositions, which are represented as given by text producers (Levinson, 1983), and therefore, they also contribute to the naturalisation of social reality.

\section{Analysis of the curricula}

a. Formation of objects. In the curriculum of 2003, an explicit reference is made to the necessity and the role of pre-school education, as described by the law and the Constitution, since the attendance to the kindergarten became compulsory only in 2006: "According to the law, the aim of the kindergarten is to help children develop physically, emotionally, mentally and socially within the framework of the broader aims of primary and sec-

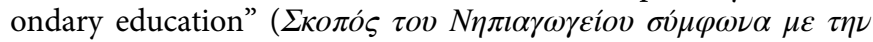

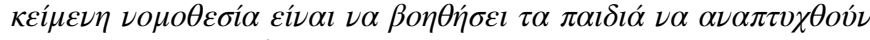

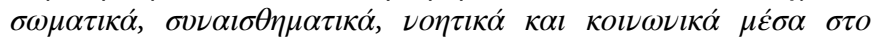

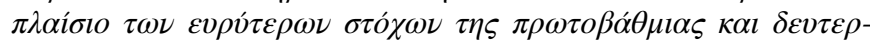

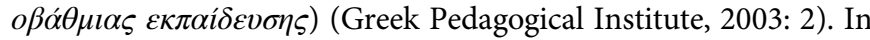
contrast, in the curriculum of 2011, no such reference is made, while the kindergarten is represented as being part of compulsory education: "changes that characterise contemporary life are so intense and rapid which require a direct adjustment of the curricula of compulsory education, in order to cope effectively with the needs of the citizen of 21st century" (oı $\alpha \lambda \lambda \alpha \gamma \varepsilon \dot{\varepsilon} \varsigma \pi 0 v \sigma \eta \mu \alpha-$

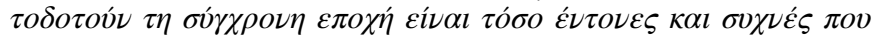

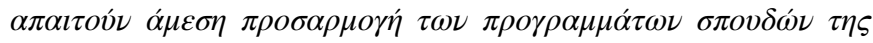

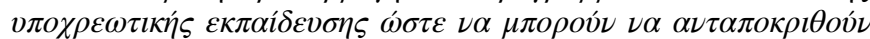

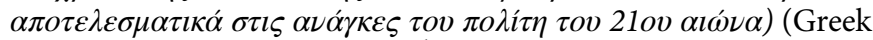
Pedagogical Institute, 2011: 3). ${ }^{1}$

In particular, the curriculum of 2003 was constructed as a new and innovative proposal for Greek education, focusing on the "cross-curricular approach" ( $\delta \imath \alpha \theta \varepsilon \mu \alpha \tau \imath \kappa \eta \dot{~} \pi \rho o \sigma \varepsilon ́ \gamma \gamma l \sigma \eta)$ it introduces. Therefore, it criticises the existing educational practice of the separate teaching of different subjects: "Yet, in this way, the 
required 'internal cohesion' and 'unified horizontal development

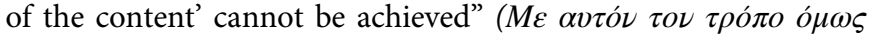

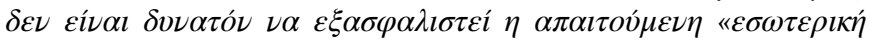

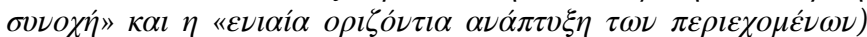
(Greek Pedagogical Institute, 2003: 5). In contrast, the curriculum of 2011 was constructed as only complementary to the previous one. Hence, there are explicit references to the text of 2003, while the "updating" and "remedial" role of the new curriculum is clearly stated: "a new curriculum does not always mean that the previous one is cancelled or that dramatic changes are proposed" (

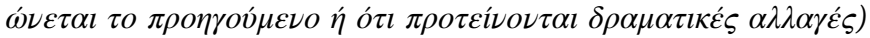
(Greek Pedagogical Institute, 2011: 5). In fact, in the first pages of the text, there is a section with the eloquent title "what is changing and what remains the same" ( $\begin{array}{llll}\tau l & \alpha \lambda \lambda \dot{\alpha} \zeta \xi \varepsilon & \kappa \alpha l & \tau l\end{array}$ $\pi \alpha \rho \alpha \mu \varepsilon \varepsilon \nu \varepsilon l \tau o$ i $\delta l o$ ), in which the basic concepts which are introduced and those which are adopted from the previous curriculum are briefly presented in a form of a list. In sum, according to the authors of the curriculum, the newly introduced concepts are: "the development of basic competencies' ( $\eta$ $\alpha \nu \alpha \dot{\tau} \tau \nu \xi \eta \beta$

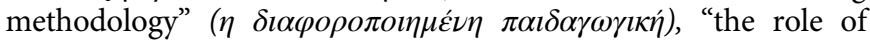

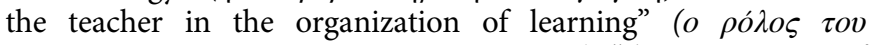

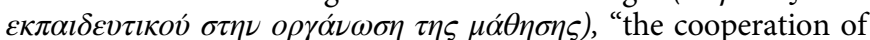
the school with the family/ the parents' involvement in children's

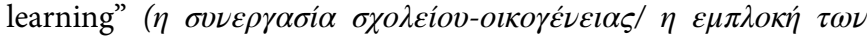

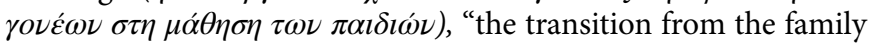
to the kindergarten and from the kindergarten to the primary

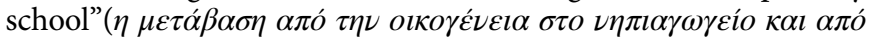

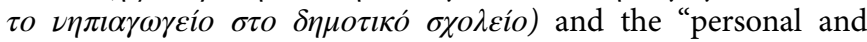

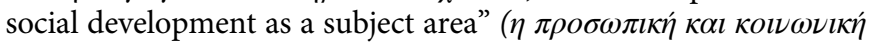
$\alpha \nu \alpha \dot{\pi} \tau \nu \xi \eta \omega \varsigma \theta \varepsilon \mu \alpha \tau \imath \kappa \dot{~} \pi \varepsilon \rho \imath о \chi \dot{\eta})$.

This gradually conceptual shift from the previous curriculum to the new one could be better understood in the context of the financial crisis and the social changes occurring over the last five years in Greece and in the E.U. Furthermore, it is worth considering the Lisbon Summit in 2000, where the political goal promoted was that in the next few years the E.U. should become the most competitive knowledge-based economy in the world. Investment in human capital and the integration of the population into the labor market were announced as the core means of achieving this aim (European Council, 2000). In a similar political vein, in 2010, the Bologna Process projected this aim upon the European educational field. So far, we have witnessed the establishment of a hegemonic force that attempts to reconstruct the social field through newfound power relations on an international and local scale. This hegemonic force is a constellation of neo-liberal practices that establish a new way of thinking about the relationship between economic and social structures, and produce new forms of subjectivity and ethics. We could claim that these neo-liberal forms of political and financial power have been partly imposed on the population through the educational system, and especially also through the curriculum.

Both curricula attempt to sketch the broader socio-economic context within which Greek (pre-school) education is situated. Specifically, in the curriculum of 2003, this context is invested with words, that is, "lexicalized", related to European values of liberal humanitarian discourse, for example, "school must constitute an exemplary institution for the implementation of the principles of human rights, such as the respect of the other... the freedom from any form of discrimination, the freedom of thought and expression, participation and cooperation" ( $\tau O$

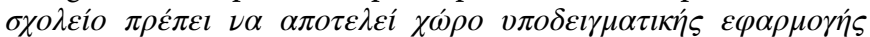

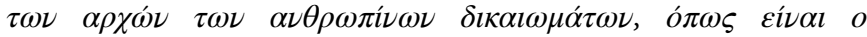

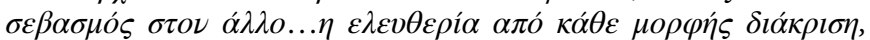

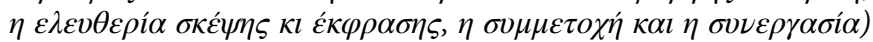

(Greek Pedagogical Institute, 2003: 5). However, at the same time, it describes the world as being "fluid" ( $\rho \varepsilon v \sigma \tau o ́)$ and "unstable" $(\alpha \sigma \tau \alpha \theta \dot{\eta})$, and thus "lifelong learning" ( $\delta l \alpha$ ßiov $\mu \alpha \dot{\theta} \theta \eta \sigma \eta)$,

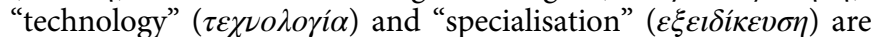
needed, drawing upon a neo-liberal discourse. On the other hand, in the curriculum of 2011, the world is represented as being so

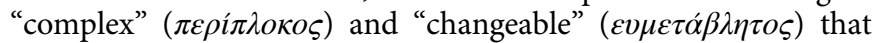
requires "flexibility" ( $\varepsilon v \varepsilon \lambda l \xi i \alpha)$ and the development of "basic

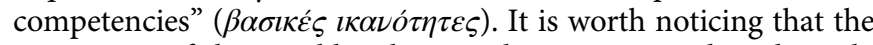
imposition of the neo-liberal rationality is presented as the only alternative by both curricula. However, this is more evident in the curriculum of 2011.

\section{b. Formation of enunciative modalities}

External conditions. The two curricula under study are the official reference texts for pre-school education currently in Greece. They have been written and published under the auspices of the Greek Ministry of Education and Religious Affairs. Therefore, they resonate the official view about childhood and pre-school education. The curriculum of 2003 is the one being currently implemented in the total of Greek pre-schools. In contrast, the curriculum of 2011 was part of a recent educational reform called

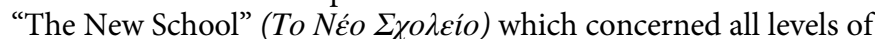
Greek education and was linked to the plans of the government of the time to implement the spirit of the Bologna Process to Greek compulsory education. This curriculum was pilot tested on a limited number of Greek kindergartens (21 schools) during the school year 2011-2012, but without the necessary preparation and training of the teaching staff. The original idea was to be extended to the whole pre-school education in the following year. Nevertheless, due to the current economic crisis in Greece, this project has been suspended.

Internal conditions. In both curricula, the Greek Ministry of Education and Religious Affairs is constructed as an "omniscient narrator" in Todorov's terms (1977). This means that the narrator's voice is represented as speaking with an absolute authority, and he writes about children, their nature and their role in the world, as if he knows everything about their behavior and dispositions or their preferences of an ideal future. This is linguistically expressed through the following mechanisms.

First, information in both texts is written in third person, and thus no interaction with the reader is constructed, offering an impersonal and formal style. Second, information is delivered in an absolute and indisputable way through the lack of epistemic modality (for example, "perhaps", "probably"), producing categorical statements about how the world in general and education in particular "are". Thus, truth in the texts is represented as non-negotiable: for example, "today children grow up in increasingly diverse societies. People need to function effectively in the context of different groups during their life"

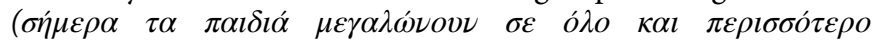

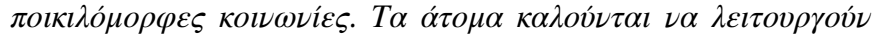

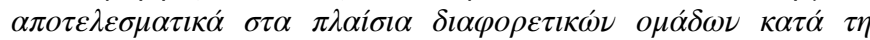

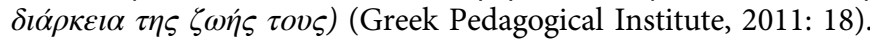
Third, through several presuppositions implied in the texts about what education and children are, information is represented as taken for granted. For instance, in the utterance "an essential cooperation between the school and the family occurs when the teacher and parents acknowledge the role both of them have in

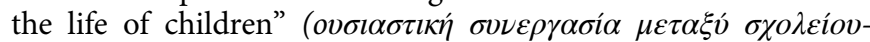

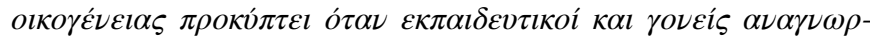

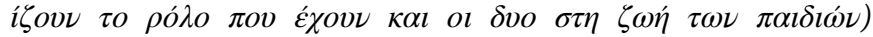
(Greek Pedagogical Institute, 2011: 51), the verb "acknowledge" presupposes that the teacher and parents have a central role in 
children's life. Furthermore, in the curriculum of 2011, information is often provided in the form of lists, and thus it is represented as non-negotiable: for example, the role of the teacher is to help the families to understand that they can create an

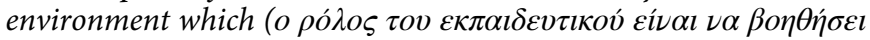

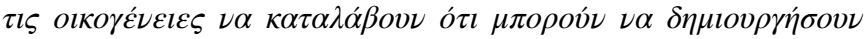
$\varepsilon \dot{\nu} \alpha \pi \varepsilon \rho \imath \beta \dot{\alpha} \lambda \lambda \circ \nu \pi o v)$ :

(a) Encourages and supports learning ( $\varepsilon \nu \theta \alpha \rho \rho \dot{\nu \varepsilon \imath ~ \kappa \alpha l ~ v \pi о \sigma \tau \eta \rho-~}$ $i \zeta \varepsilon \imath \tau \eta \mu \alpha \dot{\alpha} \theta \eta \sigma \eta)$

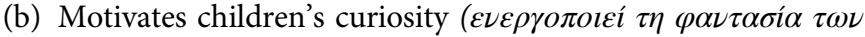
$\pi \alpha \imath \delta i \omega ́ \nu)$

(c) Expresses high and realistic expectations about children's

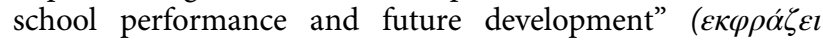

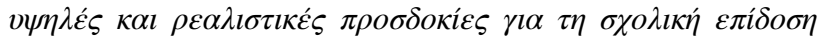

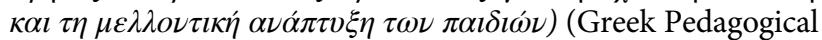
Institute, 2011: 10).

\section{c. Formation of concepts}

Childhood. The discourse analysis showed that the central concept around which knowledge is articulated in both curricula is

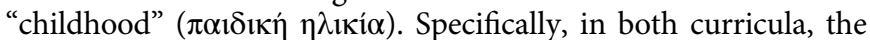
concept of childhood is constructed in a "closed" and specific way, being attached to particular attributes, which seems to justify, and even legitimise, particular actions towards children, and ultimately their control by education. Thus, in both texts, children are represented as being characterised by curiosity, enquiry, experimentality and creativity (for example, "children of this age have an inherent curiosity and want to investigate 'how' and 'why' things function the way they do in the world around them": Greek Pedagogical Institute, 2011: 33) ( $\tau \alpha \pi \alpha l \delta l \alpha$

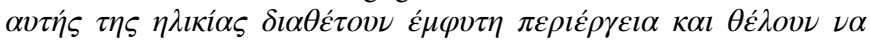

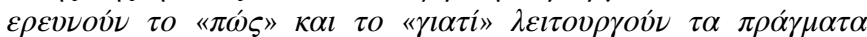

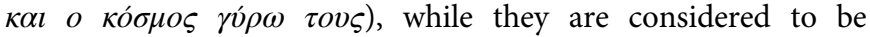
expressed through mobility and play. Moreover, the curriculum of 2003 stresses the interactional aspect of learning, echoing a Vygotskian sociocultural theory of learning: "young children discover the world through movement, enquiry and interaction.... they share their knowledge with other, exchange ideas and

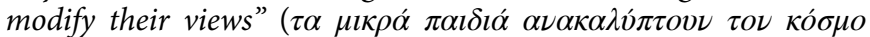

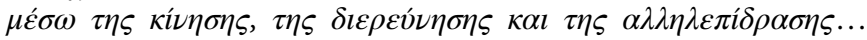

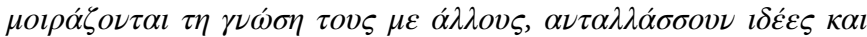

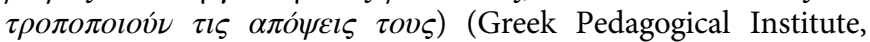
2003: 5). On the other hand, in the curriculum of 2011, the uniqueness and diversity of children is highlighted, expressing an emphasis of the more recent curriculum to issues of otherness in general.

Interestingly, the specific representation of childhood in both texts is appeared as commonsensical and taken for granted, and thus naturalised. This is achieved through the lack of epistemic modal expressions (for example, "probably", "possibly"), producing categorical assertions about what children "are". Naturalisation is also established through the use of words such as "by nature" ( $\alpha \pi \delta$ c $\tau \eta \quad \varphi v ́ \sigma \eta)$, "spontaneous" ( $\alpha v \theta \dot{\rho} \rho \mu \eta \tau o \varsigma)$ and "inherent" ( curious about the natural and social environment": Greek

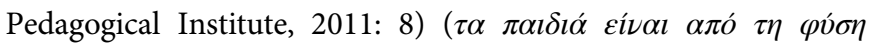

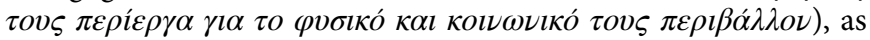
well as through generalisations with the use of "every" and "all" (for example, "every child is unique and all children have the right to an education which respects their personality" ( $\kappa \dot{\alpha} \theta \varepsilon$

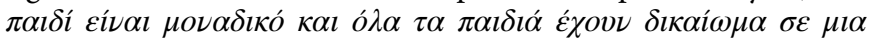
$\varepsilon \kappa \pi \alpha i \delta \varepsilon v \sigma \eta \eta$ олоі́ Pedagogical Institute, 2011: 8).
Moreover, naturalisation is achieved through several presuppositions about childhood, which are implied in the text. For instance, in the utterance "these activities awake children's curiosity, motivate their fantasy, encourage expression and

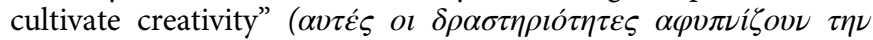

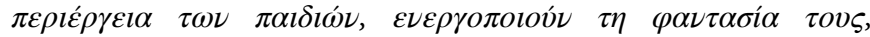

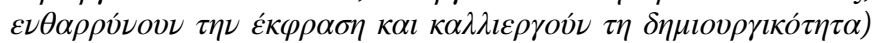
(Greek Pedagogical Institute, 2003: 7), the verbs "awake", "motivate", "encourage" and "cultivate" presuppose the existence of curiosity, fantasy, expression and creativity in children. Hence, through these presuppositions, what children are is once again represented as indisputable.

This interpretation is informed by the mainstream romantic discourse of the unbiased perception of reality by children (Jenks, 1996). According to this discourse, the child is naturally good and kind and is supposed to approach reality with a clear and pure gaze.

Also, Piaget-oriented developmental psychology still powerfully influences the Greek pre-school curricula. Within this discourse, the child is ascribed certain negative attributes such as immaturity, incompetence, dependence, etc., which justify and legitimize the intervention of adults on the children's bodies, so as to regulate and guide them towards the adult cognitive competence. However, in childhood studies, we have witnessed a shift away from the psychological perspectives considering childlren solely as becomings. Furthermore, there is no single, and universal, pre-determined model of development for all children (James and Prout, 1990). From this point of view, it is important to consider both how children experience their childhoods, and the influence of structural determinants of behavior, such as class, gender, ethnicity, and geography. In other words, it is significant to take into account the impact of social and cultural contexts upon the development of children.

In both curricula, the abovementioned modern constructions of childhood coexist with the late modern discourse of the competent and autonomous child. Specifically, in both texts, children are lexicalised through words, which give an emphasis to their competence, critical thinking and active participation to learning. Hence, the curriculum of 2003 refers to "strong selfperception" ( methods of approaching knowledge" ( $2 \nu \varepsilon \rho \gamma \eta \tau \imath \kappa \varepsilon ́ \varsigma \kappa \alpha l \sigma v \mu \mu \varepsilon$ -

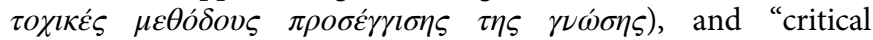

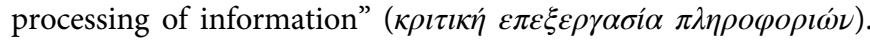
In a similar vein, in the curriculum of 2011, we read about children's "empowerment" ( $\varepsilon \nu \delta v \nu \alpha ́ \mu \omega \sigma \eta)$, "creative and critical

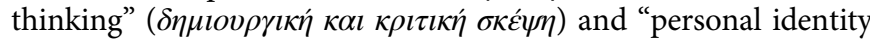
and autonomy” ( in both texts, children's active role and agency is undermined, since it is represented as being completely demarcated and controlled through particular transitivity patterns.

More analytically, in the curriculum of 2003, children's "autonomy" is represented as being mostly controlled by the school (or related abstract entities), being positioned in "agent" role: for example, "School must teach student 'how to act', so that he can apply the knowledge and skills acquired to his everyday

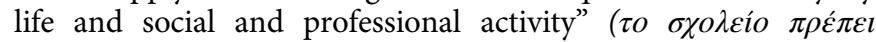

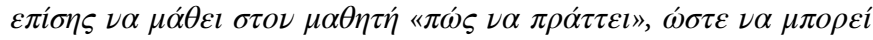

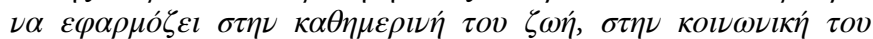

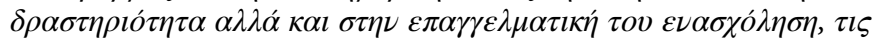

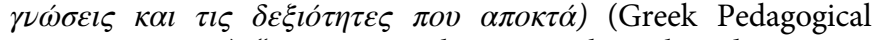
Institute, 2003: 3), "cross-curricular approach is a broader term to 'interdisciplinarity' and provides the opportunity to the student to shape... a holistic conception of knowledge, which allows him to have a personal view about interrelated scientific matters" ( $\eta$

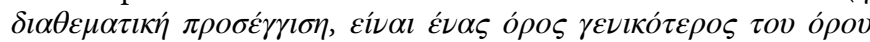




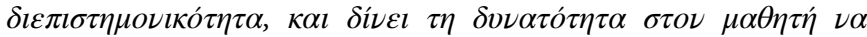

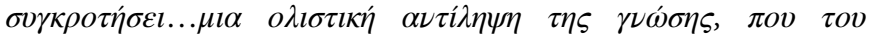

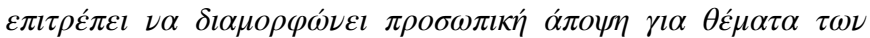

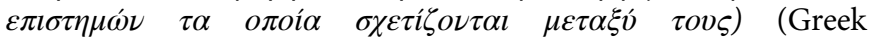
Pedagogical Institute, 2003: 8).

On the other hand, in the school curriculum of 2011, children's actions are more explicitly controlled. In particular, they are often represented in "medium" role, namely as recipients of processes initiated by teachers: "teachers adjust the degree of support of children's actions depending on their level of autonomy" (or

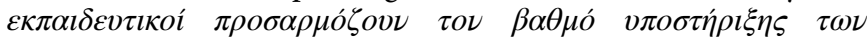

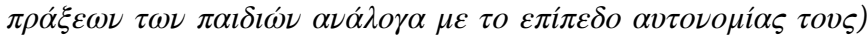
(Greek Pedagogical Institute, 2003: 18). Thus, children's agency tends to be represented as an outcome of teachers' guiding (for example, in the following example, children "make enquiries" and "gradually use more systematic ways of data collection, processing and analysis" because the teacher "motivates them" to do so). Besides, it is represented as non-negotiable and taken for granted in the form of a list. In this way, children's "autonomy" and "empowerment" is cancelled in practice: for example, Specifically,

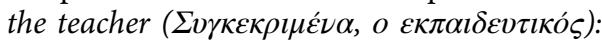

- Motivates children to make enquiries which start from their own interests and questions and to gradually use more systematic ways of data collection, processing and analysis

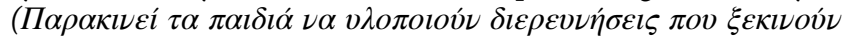

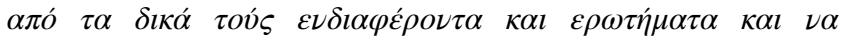

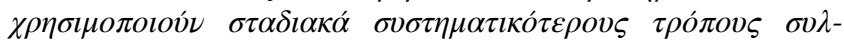

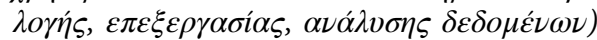

- Facilitates them to express and represent their thoughts in

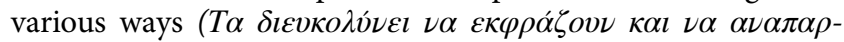

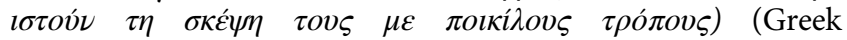
Pedagogical Institute, 2011: 14)

The development of metacognitive strategies is facilitated when the teacher, for example, ( $\eta \alpha \nu \alpha \dot{\pi} \tau v \xi \eta \tau \eta \omega \nu \mu \varepsilon \tau \alpha \gamma \nu \omega \sigma \tau \imath \kappa \omega \nu$

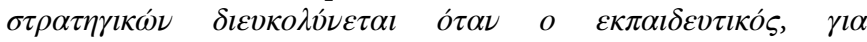
$\pi \alpha \rho \alpha ́ \delta \varepsilon \imath \gamma \mu \alpha)$ :

- Encourages children to suggest or to invent techniques and tools

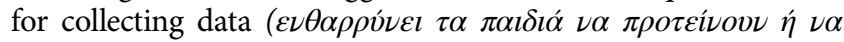

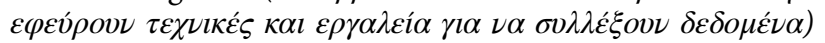

- Employs various media, such as artifacts of children themselves...in order to facilitate them to become aware of their

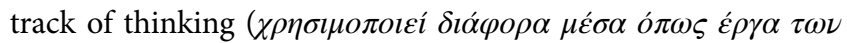

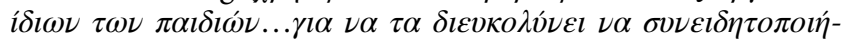

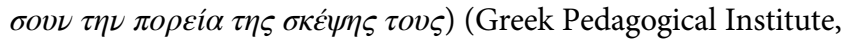
2011: 12)

In seeking to understand the paradox of acknowledging children's agency and autonomy, on the one hand, and cancelling them in practice, on the other, the significance of the current hegemonic neo-liberal rationality must be recognised. The neoliberal governmentality is based upon the apparently contradictory connection between freedom and control. Not only does governmentality function through freedom, but also, personal freedom is a form of self-control (Rose, 1989; Foucault, 1984). In other words, it is a form of power that functions through encouragement rather than suppression (Dean, 2009). Hence, governmentality operates as a "conduct of conduct", governing the individual from within by guiding his/her self-management according to specific normative standards (Foucault, 1991, 2010). Individual autonomy is exclusively perceived as the right to choose, and it is attributed to very young children, which are considered to be persons with wishes, motives and interests. However, the rights of choice, freedom and autonomy, and consequently the active participation of children in public life, are usually considered exclusively in relation to consumption and the world of goods. In this sense, we could claim that the "inherently competent child" is, after all, a guided child, which is formed by neo-liberal strategies aiming to give prominence to children's abilities for self-regulation and self-management (Smith, 2012). Moreover, within this discourse, people should be capable of working constantly on their own, in line with the demands of the global economy of knowledge. This presupposes flexible forms of socialization producing flexible subjectivities aiming at the financial success. It is worth considering that innovation, responsibility and autonomy are significant human qualities. However, within the neo-liberal discourse, they are exclusively perceived in direct relation to entrepreneurship and the market (Kelly, 2000).

Interestingly, in the rigid way children's agency is represented in the most recent curriculum, notions like "play" ( $\pi \alpha \imath \chi \nu i \delta l)$ and "enquiry" ( $\delta \varepsilon \rho \varepsilon v \dot{\nu} \eta \sigma \eta)$ also acquire the meaning of teacher's control. "Play" could be seen as a technology of governance (Ailwood, 2003), which produces the "child" according to the requirements of the hegemonic neo-liberal discourse. "Play" produces the "child" as the subject of this discourse. Specifically, play is divided into the "free" $(\varepsilon \lambda \varepsilon v \theta \varepsilon \rho o)$ and "organised" (о $\gamma \alpha \nu \omega \mu \varepsilon ́ \nu o)$ ones, while even "free play" is represented as a tool at teacher's hands for the gathering of information and children's assessment: "while observing children during free play, teachers identify interests, preferences, they testify knowledge and skills [children] have already acquired and attitudes [children] have

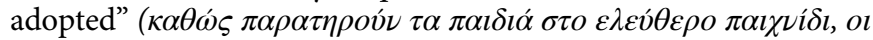

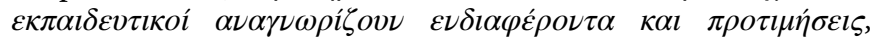

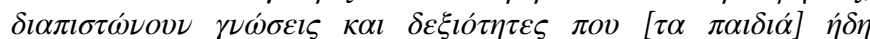

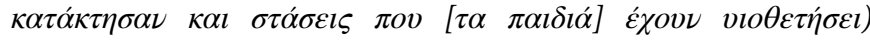
(Greek Pedagogical Institute, 2011: 29). Similarly, enquiry is represented as a procedure, which is guided and controlled by the teacher to be "effective": "enquiries constitute an appropriate setting for learning...However, curiosity by itself does not always and automatically lead to learning. The teacher's intervention is necessary for the formation of learning experiences which will not only exploit the inherent curiosity of children but which will also

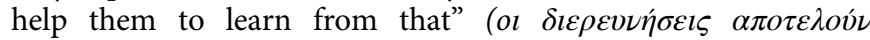

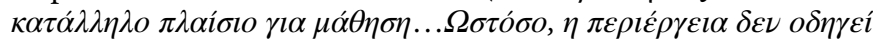

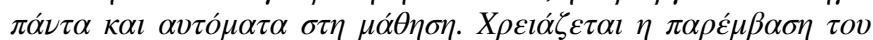

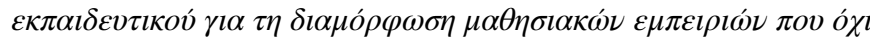

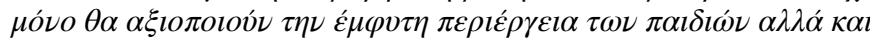

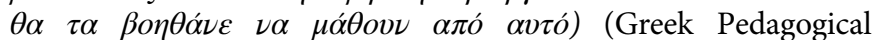
Institute, 2011: 33). In this sense, both "play" and "enquiry" bear specific normative standards of observation, surveillance, and intervention upon children's bodies.

\section{d. Formation of strategies}

The role of (pre-school) education. In the school curriculum of 2003, the role of education is constructed around a vocabulary which underlines a liberal dimension of knowledge: "equal opportunities

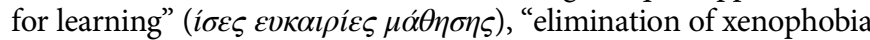

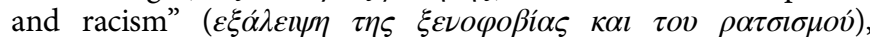

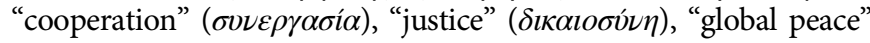
( $\pi \alpha \gamma \kappa o ́ \sigma \mu \imath \alpha \varepsilon \iota \rho \dot{\eta} \nu \eta)$ and "human rights" ( $\alpha \nu \theta \rho \omega ́ \pi \imath \nu \alpha \delta \imath \kappa \alpha \iota \omega \mu \alpha \tau \alpha)$ : "the educational procedure must create conditions for the promotion of the values of democracy, of the respect of human rights, of peace and freedom" ( $\eta \varepsilon \kappa \pi \alpha l \delta \varepsilon v \tau \imath \kappa \eta \dot{~} \delta \imath \alpha \delta \imath \kappa \alpha \sigma i \alpha \pi \rho \varepsilon \dot{\pi} \pi \imath \nu \alpha$

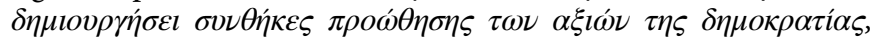

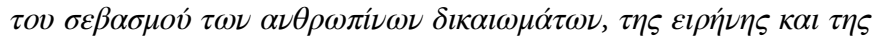
$\varepsilon \lambda \varepsilon v \theta \varepsilon \rho i \alpha \varsigma)$ (Greek Pedagogical Institute, 2003: 3). Moreover, the alignment of Greek education to the educational policy of European Union is stressed: "Besides, the orientation of European 
Union for education is similar. The preservation of the democratic character of political life, of freedom...of spiritual cultivation and social cohesion in open pluralistic societies frame the common

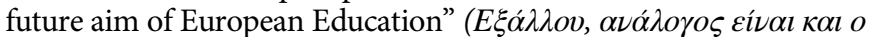

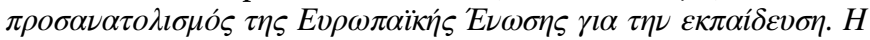

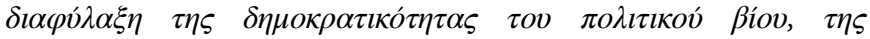

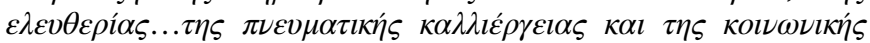

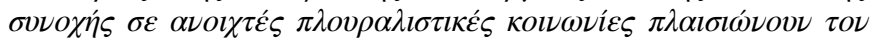

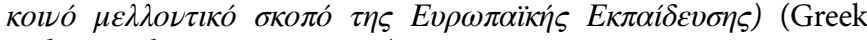
Pedagogical Institute, 2003: 4)

However, this liberal dimension is usually related to a utilitarian and economic dimension of knowledge, by giving emphasis to the "fluidity" of the contemporary social, political, economic and cultural environment, which requires "lifelong learning" ( $\delta l \alpha$ Biov $\mu \alpha \dot{\alpha} \theta \eta \sigma \eta)$, "Information and communication technologies" (

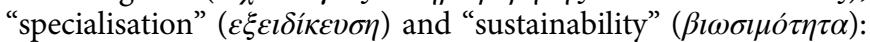
"the various social, political, economic and cultural conditions of our time are characterised by fluidity, which is intensified due to the rapid scientific and technological development. In this context, the indisputable role of the school as a central social institution of providing knowledge and developing skills seems to

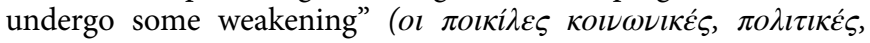

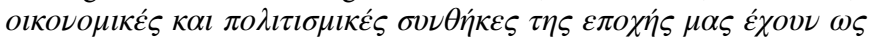
кú

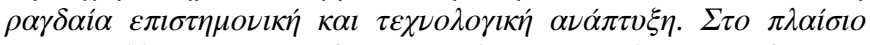

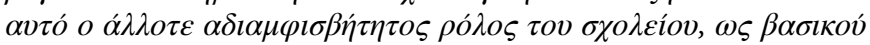

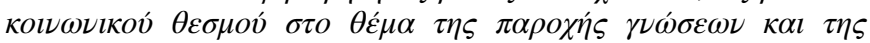

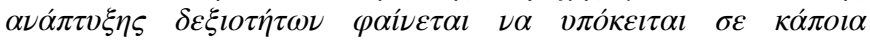
$\alpha \pi о \delta v \nu \alpha ́ \mu \omega \sigma \eta)$ (Greek Pedagogical Institute, 2003: 2). In this context, the proposed teaching methodology in the curriculum focuses on "the flexible zone" ( $\varepsilon v \varepsilon \dot{\lambda} \imath \kappa \tau \eta \zeta \omega \nu \eta)$ (meaning the teaching hours devoted to projects designed by the teacher on subjects of his/her selection), on "innovative educational projects"

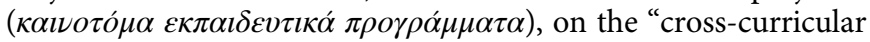

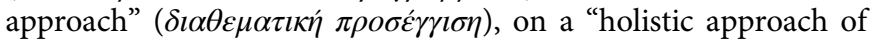

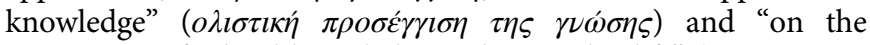
connection of school knowledge with everyday life" ( $\sigma \dot{\nu} \nu \delta \varepsilon \sigma \eta \tau \eta \varsigma$

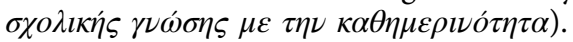

On the other hand, in the more recent curriculum of 2011, a neo-liberal discourse is clearly drawn upon for the construction of the role of education, by highlighting a purely economic and utilitarian dimension of knowledge. Specifically, education is contextualised throughout the whole text within the social conditions of the time and the priorities set by the E.U.: for example, "changes in the last decade since the introduction of the curriculum of 2003 in Greek schools, such as the implementation of the compulsory attendance to the kindergarten...the development of 'basic competencies' which will help citizens to cope with the challenges of the 21st century, have created the need for the revision and improvement of the previous school curriculum"

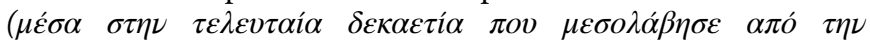

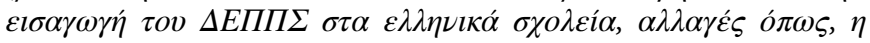

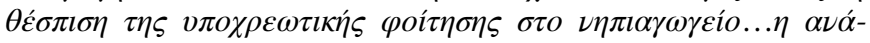

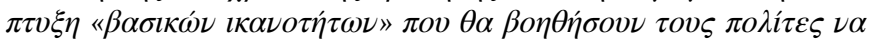

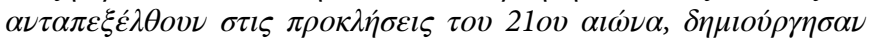

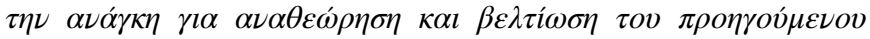

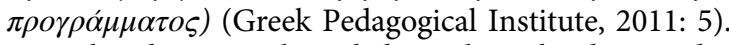

In this discourse, knowledge is lexicalised around words such

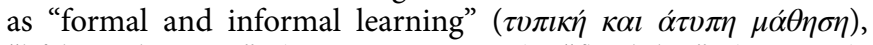

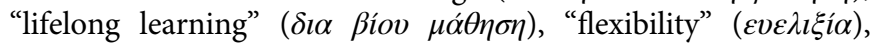
while a particular emphasis is given to the four "basic

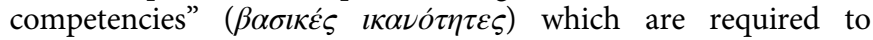
develop, based on the national and European strategic plan for education, namely on "communication" ( and critical thinking" ( identity and autonomy" (

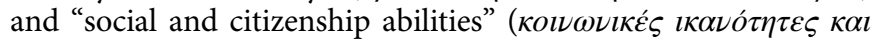

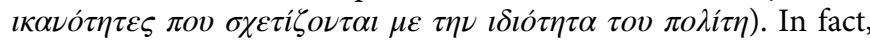
the curriculum is divided into four relevant sections, in which each "basic competency" is elaborated in detail. Interestingly, before the description of each competency, a question is preceded of the type: "why is it the building of children's personal identity and the development of autonomy particularly important today?"

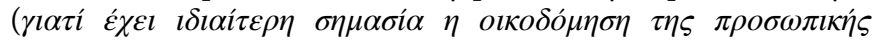

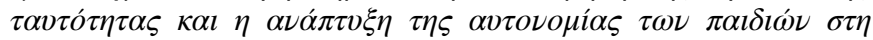

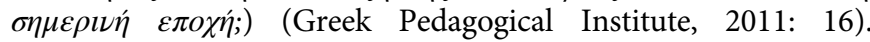
Consequently, the proposed teaching methodology in the curriculum of 2011 also focuses on "projects" ( $\pi \rho \circ \gamma \rho \alpha \dot{\mu} \mu \alpha \tau \alpha)$ and on the "cross-curricular approach" ( $\delta l \alpha \theta \varepsilon \mu \alpha \tau \imath \kappa \dot{n} \pi \rho o \sigma \varepsilon \dot{\gamma} \gamma l \sigma \eta)$, but it additionally introduces the "differentiated teaching

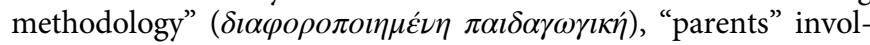

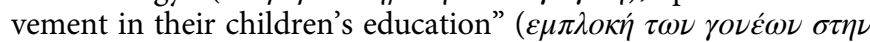
$\varepsilon \kappa \pi \alpha i ́ \delta \varepsilon v \sigma \eta \tau \omega \nu \pi \alpha l \delta l \omega \nu \tau \sigma o v \varsigma$ ), and "transition programs from the family to the kindergarten, and from the kindergarten to the

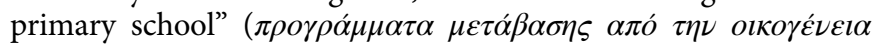

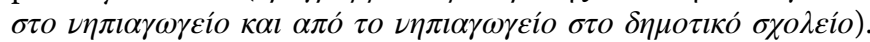

The educational management of diversity. In the curriculum of 2003, the management of diversity in education is discussed in a liberal context of human rights: for example, "school must constitute an exemplary institution for the implementation of the principles of human rights, such as the respect of the other...the freedom from any discrimination..." (

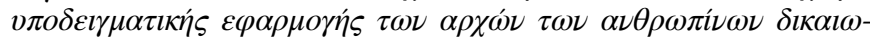

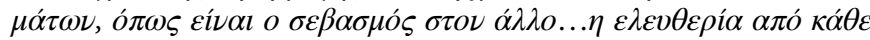

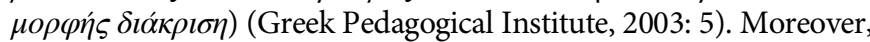
it is related to the liberal values of Europe: "Besides, it is a position held by all EU countries, namely the protection of the particularity of national education and the acceptance of national diversities, and thus, of those elements which contribute to the shaping of the national and cultural identity of student-future citizen" ( $E \xi \dot{\alpha} \alpha \lambda \lambda_{0 v}$,

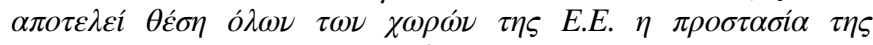

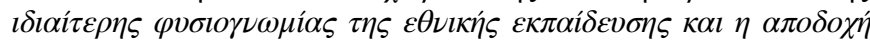

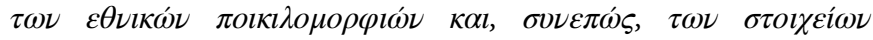

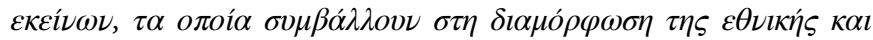

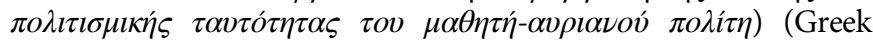
Pedagogical Institute, 2003: 4). On the other hand, a special focus is given on disability as a dimension of diversity, reflecting the fact that special education and inclusive programs were systematically organised the time in which the text was written.

In contrast, in the school curriculum of 2011, diversity acquires a different meaning, being discussed in the context of "differentiated teaching methodology" (

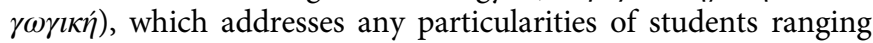
from cultural diversity and social class, to disability, gender, family structure and learning styles: "this diversity includes demographic dimensions like gender, age, national or local origin, socio-economic groups, mother tongue and special needs, as well as dimensions related to different lifestyles, such as experiences, interests, friends, values, attitudes, way of thinking and learning

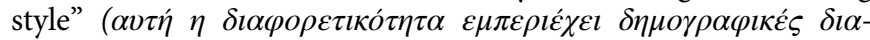

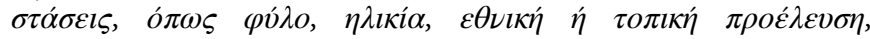

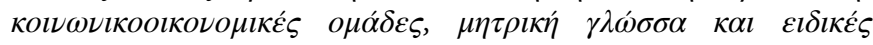

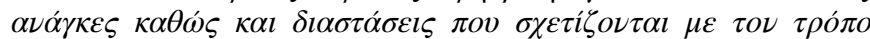

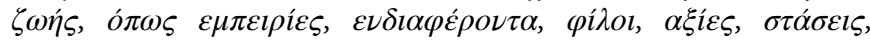

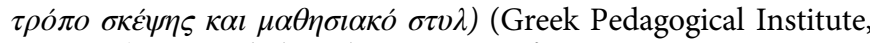
2011: 21). Nevertheless, by equating, for instance, immigration with divorce (for example, "the unproblematic inclusion of children to categories on the basis of one feature or their treatment as a representative case of a specific group (for example, 'child of immigrant parents' or 'child of divorced 
parents') is bound to lead to simplified discriminations...": Greek Pedagogical Institute, 2011: 21) ( $\eta \alpha \beta i \alpha \sigma \tau \eta \dot{\varepsilon} \nu \tau \alpha \xi \eta \tau \omega \nu \pi \alpha l \delta i \omega \nu$

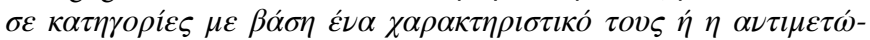

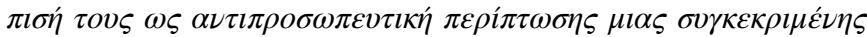

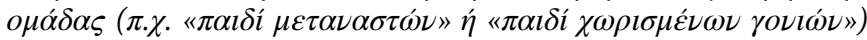

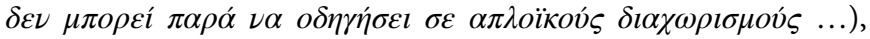
diversity is neutralised and decontextualised, while it is more presented as an attribute of the individual rather than of society.

The teacher's role. In the school curriculum of 2003, the teacher's role is not much visible. In particular, his agency tends to be deemphasised through agentless passive syntactic constructions (for example, "In the kindergarten, opportunities must be given to the children to explore elements from the human-made environment and learn more things about themselves": Greek Pedagogical

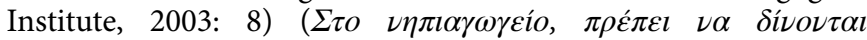

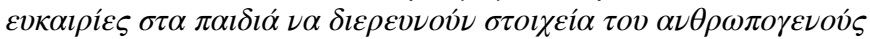

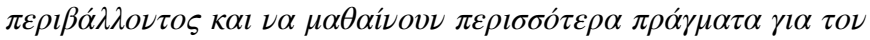

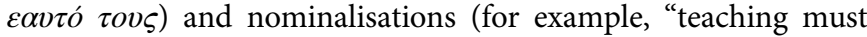
lead to the widening of cognitive structures": Greek Pedagogical

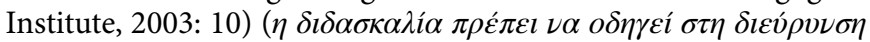

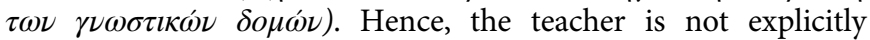
mentioned in the text, but only expected to be implied by the reader. Interestingly, in most of the cases, the deontic modal verb "must" $(\pi \rho \dot{\varepsilon} \pi \varepsilon l)$ is used. Since, in principle, modality is a linguistic mechanism through which truth is not represented as given, but a doubt is signaled about what we are saying, the use of "must" indicates that the teacher's role is not taken for granted, but it is rather negotiable in the text.

In some cases, the teacher's role is only implicitly meant through metonymies (for example, "suitable activities", in the following example), but instead, children's agentive role is stressed: for example, "In the kindergarten, through suitable activities, children identify the beauty of the natural environment and of the art works that they encounter" ( $\Sigma \tau o \nu \eta \pi \iota \alpha \gamma \omega \gamma \varepsilon i o, \mu \varepsilon \varepsilon \sigma \alpha$

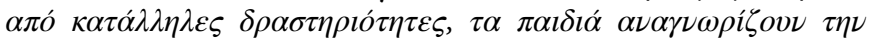

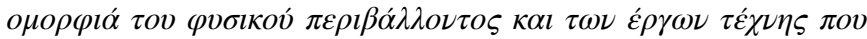

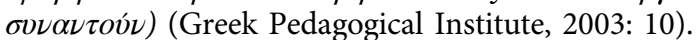

In very few cases, teacher's agency is linguistically foregrounded through active syntactic constructions: for example, "the pre-school teacher must inform parents about the overall

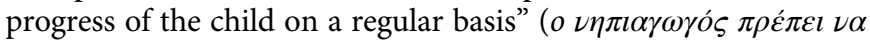

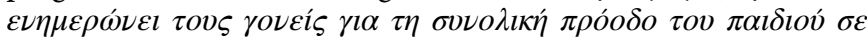

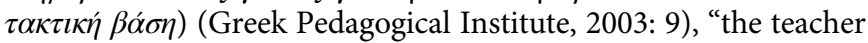
observes and records elements which he considers important" $(o$

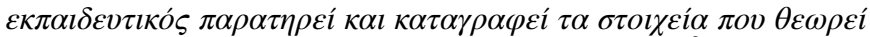
$\sigma \eta \mu \alpha \nu \tau \imath \kappa \alpha ́$ ) (Greek Pedagogical Institute, 2003: 12). ${ }^{2}$

Resonating the discourse of child-centered pedagogy, the teacher is represented in the curriculum of 2003 as a facilitator of the learning process and children's agency. In this way, the teacher is not represented as being an agent of processes targeted to children, but he is constructed as planning activities and creating the conditions for children's agency. Thus, he is limited to mostly initiate mental processes (for example, "motivate", "encourage") targeted to children: "the teacher motivates children to listen to music and to play 'with music'..." (о $\varepsilon \kappa \pi \alpha l \delta \varepsilon v \tau \imath \kappa o ́ \varsigma$

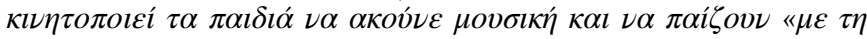

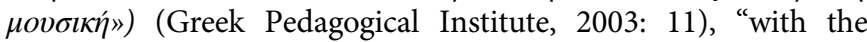
assistance of the teacher, children are encouraged to approach basic concepts related to the computer" ( $\mu \varepsilon \tau \eta \sigma v \nu \delta \rho o \mu \eta$ i $\tau o v$

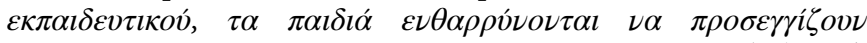

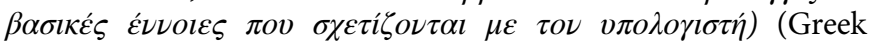
Pedagogical Institute, 2003: 9).

In contrast, in the school curriculum of 2011, the teacher is represented as having an active role in the learning process. In fact, in the text, it is explicitly mentioned that the foregrounding of the teacher's role is a conceptual shift from the curriculum of 2003: "what is it changing? A stress is put on the teacher's role in the organisation of learning and teaching" ( $\tau \iota \alpha \lambda \lambda \dot{\alpha} \zeta \varepsilon l$; Tovi $\zeta \varepsilon \tau \alpha l$

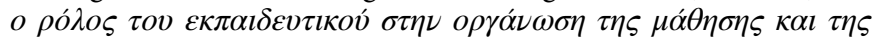
$\delta i \delta \alpha \sigma \kappa \alpha \lambda i \alpha \varsigma)$ (Greek Pedagogical Institute, 2011: 6). Hence, teacher's agency is linguistically stressed through active syntactic constructions: for example, "the teacher functions in a flexible way and adjusts the learning goals, the methodology and the

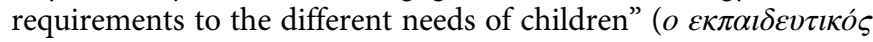

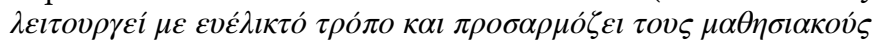

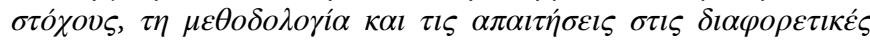
$\alpha \nu \alpha ́ \gamma \kappa \varepsilon \varsigma \tau \omega \nu \pi \alpha l \delta \iota \omega ́ \nu)$ (Greek Pedagogical Institute, 2011: 36). More importantly, contrary to the curriculum of 2003, teacher's agency is represented as non-negotiable, but rather given, through the lack of deontic modal expressions (for example, "must", "should"), and by being often described in the form of lists. In that way, it is taken for granted and becomes naturalised: "As differentiated teaching is defined the teaching approach according to which teachers, by prioritising the readiness, interests and learning profile of each student or of small groups of students $(\Omega \varsigma$

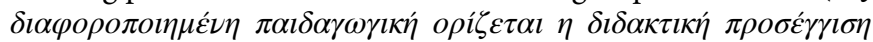

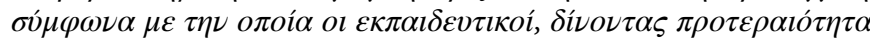

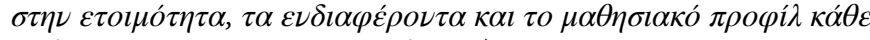
$\mu \alpha \theta \eta \tau \dot{\eta} \dot{\eta} \mu \iota \kappa \rho \dot{\nu} о \mu \alpha \dot{\alpha} \omega \nu \mu \alpha \theta \eta \tau \omega \dot{\omega}):$

\section{- Design projects $(\sigma \chi \varepsilon \delta i \alpha ́ \alpha \zeta o v \nu \pi \rho o \gamma \rho \alpha ́ \alpha \mu \alpha \tau \alpha)$}

- Choose teaching methodologies, strategies and teaching media

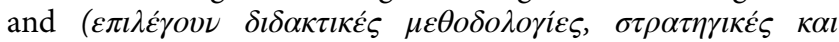

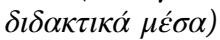

- Organize learning activities which correspond to their [stu-

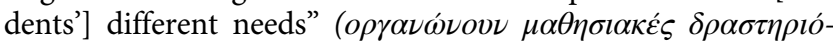

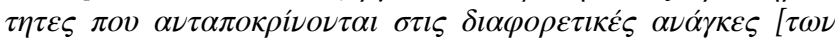

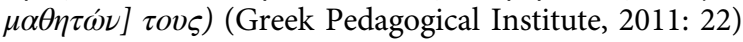

Being in agentive role, the teacher is frequently represented as controlling children's own agency by being constructed as a mediator of their actions. Teacher's control over children is located in the cognitive domain, by being represented as initiating mental processes targeted to them (for example, "motivate" and "support", in the following examples): for example, "the teacher motivates children to make enquiries and start from their own

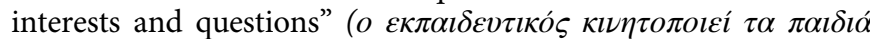

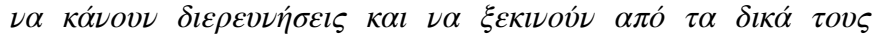
$\varepsilon \nu \delta \imath \alpha \varphi \varepsilon ́ \rho o \nu \tau \alpha \kappa \alpha l \quad \varepsilon \rho \omega \tau \dot{\eta} \mu \alpha \tau \alpha)$ (Greek Pedagogical Institute, 2011: 33), "by supporting such activities, teachers contribute to the development of the communicative competence of young

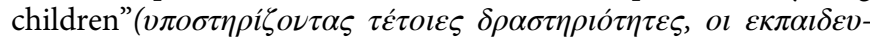

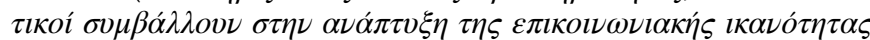
$\tau \omega \nu \mu \imath \kappa \rho \omega ́ \nu \pi \alpha \imath \delta \imath \omega \dot{\nu})$ (Greek Pedagogical Institute, 2011: 21).

Interestingly, although at some points in the text, teacher and children are represented as acting as equal partners in the learning process (for example, "the child and the teacher share the 'control' of the learning process...so learning can emerge spontaneously or be organised by the teacher with specific aims")

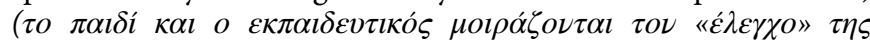

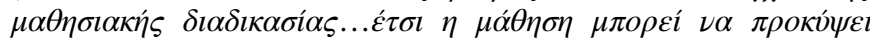

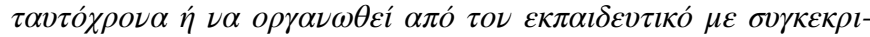

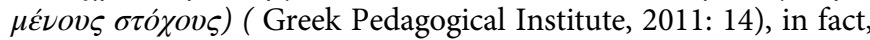
it is the teacher who is represented at the end as controlling the whole procedure. However, in such cases, the teacher's agentive role tends to be linguistically de-emphasized, through agentless passive syntactic structures, while children's agency is completely controlled and demarcated, by being represented in the form of lists. So, in the following example, children are represented as initiating processes in subordinate clauses, which are preceded by a main clause in which the teacher is implied as the agent ("the 
development of communicative competence is promoted"). Thus, children's agency is represented as being pre-determined by the teacher: for example,

"The development of communicative competence is promoted

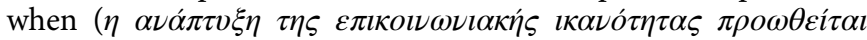
ó $\tau \alpha \nu)$ :

- Children share traditional stories and symbols from their

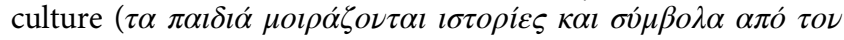

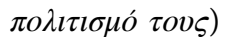

- They represent known and famous stories through creative art

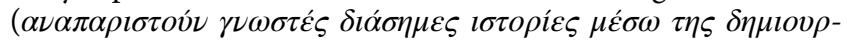

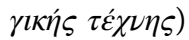

- They create and explore fictional worlds through dramatisa-

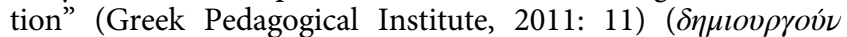

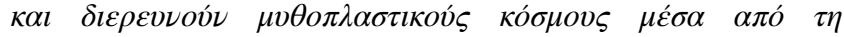

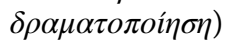

Moreover, as the new curriculum emphatically advocates "parents' involvement" in their children's education, the teacher is often represented as agent of processes targeted to parents, through active syntax: for example, "it is necessary that the teacher is able to indicate parents the different dimensions of

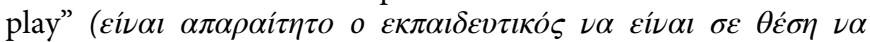

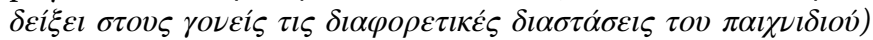
(Greek Pedagogical Institute, 2011: 30). As parents are constantly represented in "medium" role, namely as recipients of processes initiated by teachers, "parents' involvement" ( $\eta \varepsilon \mu \pi \lambda о \kappa \eta \dot{~} \tau \omega \nu$

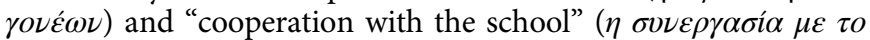

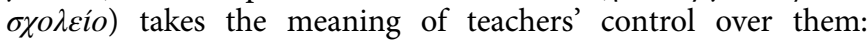
"Cooperation with the family and its involvement in the educational process can take various forms ... In each case, the teacher shows an understanding about the difficulties that families might encounter at home, as well as he advises them and guides them in order to find solutions with the problems that

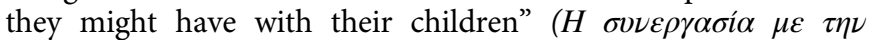

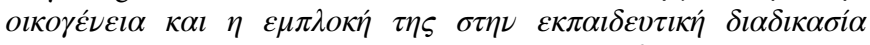

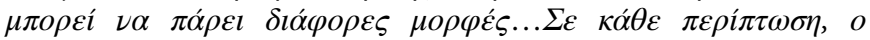

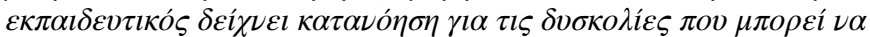

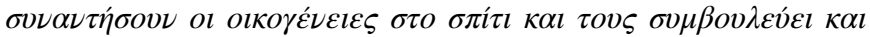

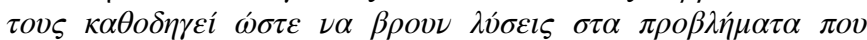

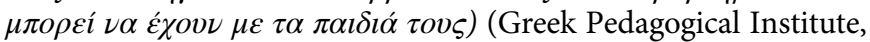
2011: 25).

A strong connection between family and educational success becomes evident in the 2011 curriculum. The specific point about this cooperation is that the State has an interest in exercising more control over young children and their families (Donzelot, 1997). Parents' involvement in their children's education can be understood as a strategy of economisation (Hübenthal and Ifland, 2011), and as a vital part of a wider neo-liberal governmental biopolitical technology. In other words, this discursive strategy can be considered as an important contribution to the economic growth and competitiveness of the Greek economy.

\section{Conclusions}

The objective of this article was to explore the forms of knowledge that were produced around early childhood and schooling by the most recent curricula of the Greek pre-school educational system $(2003,2011)$, and to address the governing aspects of these formal pedagogical discourses. From the discourse analysis, it appears that both curricula actively engage in the discursive struggle for hegemony in society, producing a specific understanding of childhood and schooling, and proposing a way to handle them.

In particular, according to our analysis, both curricula echo a neo-liberal discourse, which could exert a particular ideological power upon young children's subjectivity, namely the way they might think, feel, and act. The core ideal of neo-liberal discourse is antagonism, and consequently, the construction of the antagonistic human being. Both curricula represent the antagonism as inevitable, and the only way to regulate and organise social relations and social life. In other words, they naturalise this ideal and they argue that young children should build their human capital to be more competitive and productive as future skillful workers in the global economy of knowledge.

It is important to mention that different discourses define the nodal points (for example, "antagonism") in different ways; therefore, there is a struggle to fix meanings in terms of one discourse or another. In this (neo-liberal) discursive context, "antagonism" has a very different meaning from other conceptualisations, such as within the School of Essex. In particular, according to Laclau and Mouffe (1985), social antagonism is inevitable amongst divergent discourses around a situation or event, practice etc. Each discourse produces a specific understanding of the situation, and proposes a way to handle it. In other words, discourses compete for hegemony in society, to prevail as "the only truth".

The most recent curriculum of 2011 was found to be even more focused on the neo-liberal ideological project. In particular, in the curriculum of 2003, a liberal discourse about human rights, equal educational opportunities, freedom of thought and expression coexists with the neo-liberal discourse of flexibility, entrepreneurship, market, personal responsibility and competitiveness. Yet, in the curriculum of 2011, the political section of the liberal discourse is abandoned. Furthermore, children's governance through the teacher is more explicit and naturalised, via particular linguistic options, such as active syntax, presuppositions, and the lack of deontic modality. This conceptual shift could be understood in the current context of the hegemony of the neo-liberal ideology in the social field, where the financial section of liberal discourse has overshadowed the political one.

Moreover, it should be noted that both curricula contain several child-oriented elements such as defining children as active learners with individual needs, as well as participants in their socialisation process. However, these child-oriented elements could probably function as a subtle instrument for achieving the aims of the neo-liberal hegemonic discourse. We have attempted to demonstrate how a participatory child-centered ideology is an effective contribution to self-regulation according to the normative standards of neo-liberalism. Furthermore, we have claimed that the neo-liberal governance works through a child-oriented family-school correspondence. Also, in both curricula, traditional psychological perspectives of seeing childhood as a transitional stage of life to "become" adults coexist with a view of young children as "beings", who fully participate in social life on their own terms. Although in childhood research a shift away from the psychological perspectives considering children as becomings has been witnessed (James et al., 1998), Piaget-oriented developmental psychology still powerfully influences the Greek preschool curricula.

However, we would like to stress that children do not passively receive the content addressed to them, since they filter messages through their prior experience, knowledge and beliefs. Therefore, further research on the relationship between representations and subjective experiences is deemed necessary. Also, the way a curriculum is materialised by teachers in classrooms is another open issue, which needs further investigation.

Finally, in our study, we propose a discourse analytical approach, which combines Foucauldian with critical discourse analysis. We hope to have shown that such a synthesis is fruitful for deepening our understanding on both the socio-political dimensions of the linguistic choices of the curricula for the representation of childhood and the linguistic underpinnings of 
the discursive construction of childhood. We would like to emphasise the need for synthetic and multiperspectival frameworks, as they can cast light on a social phenomenon from diverse angles, producing a wider understanding of the phenomenon at hand, and taking into account its complexity (Jørgensen and Phillips, 2002). Besides, they also suit critical research, as different perspectives can offer diverse forms of knowledge and underline the multiple understandings and constructions of social reality.

\section{Notes}

1 The analysis was made to the original Greek text. The Greek text was translated into English by the authors, making sure to keep as much as possible the vocabulary, transitivity, modality and personal deixis patterns of the source text (for similar critical discourse analyses on Greek language data, see Avgitidou and Stamou (2013); Stamou (2001); see also Koutsogiannis and Mitsikopoulou (2003); Archakis and Tsakona (2010).

2 Throughout the text, we keep the sexist masculine gender for the "teacher", following the Greek original text.

\section{References}

Ailwood J (2003) Governing early childhood education through play. Contemporary Issues in Early Childhood; 4 (3): 286-297.

Archakis A and Tsakona V (2010) "The wolf wakes up inside, grows werewolf hair and reveals all their bullying": The representation of parliamentary discourse in Greek newspapers. Journal of Pragmatics; 42 (4): 912-923.

Avgitidou S and Stamou AG (2013) Constructing childhood: Discourses about school violence in the daily press. Children \& Society; 27 (3): 174-183.

Crouch C (2004) Post - Democracy. Polity: Cambridge, UK.

Dean M (2009) Governmentality. Power and Rule in Modern Society. Sage: London.

Donzelot J (1997) The Policing Of Families. Johns Hopkins University Press: Baltimore, MD.

Doxiadis K (2011) Discourse Analysis: A Social-Philosophical Grounding. Common Ground: Champaign, IL.

European Council. (2000) March 23 and 24, http://www.europarl.europa.eu/ summits/lis1_en.htm.

Fairclough N (1992) Discourse and Social Change. Polity Press: Cambridge, UK.

Foucault M (1984) What is Enlightenment? In: Rabinow P (ed). The Foucault Reader. Random House, Inc: New York, pp 32-50.

Foucault M (1991) Governmentality. In: Burchel G, Gordon C and Miller P (eds). The Foucault Effect: Studies in Governmentality. Harvester Wheatsheaf: London, pp 87-104.

Foucault M (2008) The Archaeology of Knowledge. Routledge: London.

Foucault M (2010) The Birth of Biopolitics: Lectures at the College de France. 19781979 (Lectures at the College de France) Palgrave Macmillan: New York.

Greek Pedagogical Institute. (2003) Unified Cross-Curricular Framework for the Curriculum of Pre-School Education. Greek Ministry of Education and Religious Affairs-Greek Pedagogical Institute: Athens, Greece.

Greek Pedagogical Institute. (2011) The New School: Curriculum of Pre-School Education. Greek Ministry of Education and Religious Affairs-Greek Pedagogical Institute: Athens, Greece.

Haldar M and Engebretsen E (2014) Governing the liberated child with selfmanaged family displays. Childhood; 21 (4): 475-487.

Halliday MAK (1994) An Introduction to Functional Grammar. Edward Arnold: London.

Hübenthal M and Ifland AM (2011) Risks for children? Recent developments in early childcare policy in Germany. Childhood; 18 (1): 114-127.

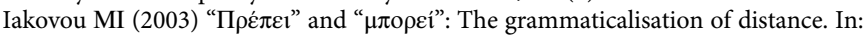
Theofanopoulou-Kontou D, Lascaratou C, Sifianou M, Giorgafentis M and Spiropoulos V (eds). Contemporary Trends in Greek Linguistics: Papers in Honour of Irene Philippaki-Warburton. Ekdoseis Pataki: Athens, Greece, pp 299-319.

James A and Prout A (eds) (1990) Constructing and Reconstructing Childhood: Contemporary Issues in the Sociological Study of Childhood. Falmer Press: London.

James A, Jenks C and Prout A (eds) (1998) Theorising Childhood. Polity Press: Cambridge, UK.

Jenks C (1996) Childhood. Routledge: London.

Jørgensen M and Phillips L (2002) Discourse Analysis as Theory and Method. Sage: London.
Kelly P (2000) The dangerousness of youth-at-risk: the possibilities of surveillance and intervention in uncertain times. Journal of Adolescence; 23 (4): 463-476.

Koutsantoni D (2005) Certainty across cultures: A comparison of the degree of certainty expressed by Greek and English speaking scientific authors. Intercultural Pragmatics; 2 (2): 121-149.

Koutsogiannis D and Mitsikopoulou B (2003) Greeklish and greekness: Trends and discourses of "glocalness". Journal of Computer-Mediated Communication. 9, http://jcmc.indiana.edu/vol9/issue1/kouts_mits.html.

Laclau E and Mouffe C (1985) Hegemony and Socialist Strategy. Verso: London; New York.

Levinson SC (1983) Pragmatics. Cambridge University Press: Cambridge, UK.

Liao J and Markula P (2009) Reading media texts in women's sports: Critical discourse analysis and Foucauldian discourse analysis. In: Markula P (ed). Olympic Women and the Media: International Perspectives. Palgrave Macmillan: Basingstoke, UK, pp 30-49.

Lyons J (1977) Semantics. Vol. 2 Cambridge University Press: Cambridge.

Lyons J (1979) Deixis and anaphora. In: Myers T (ed). The Development of Conversation and Discourse. Edinburgh University Press: Edinburgh, UK, pp 88-103.

Mouffe C (2005) On the Political. Routledge: London, New York.

Olson M, Fejes A, Dahlstedt M and Nicoll K (2014) Citizenship discourses: Production and curriculum. British Journal of Sociology of Education; 36 (7) 1036-1053.

Parton N (2014) The Politics of Child Protection. Contemporary Developments and Future Directions. Palgrave Macmillan: Basingstoke, UK.

Rose N (1989) Governing the Soul. Routledge: London.

Silcock M, Payne D and Hocking C (2016) Governmentality within children's technological play: Findings from a critical discourse analysis. Children of Society; 30 (2): 85-95.

Smith K (2012) Producing governable subjects: Images of childhood old and new. Childhood; 19 (1): 24-37.

Stamou AG (2001) The representation of non-protesters in a student and teacher protest: A critical discourse analysis of news reporting in a greek newspaper. Discourse \& Society; 12 (5): 653-680.

Todorov T (1977) The Poetics of Prose. Wiley-Blackwell: London.

Trew T (1979) "What the papers say": Linguistic variation and ideological difference. In: Fowler R, Hodge R, Kress G and Trew T (eds). Language and Control. Routledge and Kegan Paul: London, pp 117-156.

Tsangalidis A (2001) Modality criteria: The category of modal particles of Modern Greek. Studies in Greek Linguistics; 21, 759-770.

Van Dijk TA (1991) Racism and the Press. Routledge: London.

Widdowson H (1998) The theory and practice of critical discourse analysis. Applied Linguistics; 19 (1): 136-151.

Wodak R (2001) What CDA is about: A summary of its history, important concepts and its developments. In: Wodak R and Meyer M (eds). Methods of Critical Discourse Analysis. Sage: London, pp 1-13.

\section{Data availability}

The datasets analysed during the current study are available at: http://ebooks.edu.gr/new/ ps.php

\section{Additional information}

Competing interests: The authors declare that they have no competing interests

Reprints and permission information is available at http://www.palgrave-journals.com/ pal/authors/rights_and_permissions.html

How to cite this article: Pechtelidis Y and Stamou AG (2017) The "competent child" in times of crisis: a synthesis of Foucauldian with critical discourse analysis in Greek preschool curricula. Palgrave Communications. 3:17065 doi: 10.1057/palcomms.2017.65

Publisher's note: Springer Nature remains neutral with regard to jurisdictional claims in published maps and institutional affiliations.

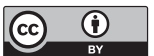

This work is licensed under a Creative Commons Attribution 4.0 International License. The images or other third party material in this article are included in the article's Creative Commons license, unless indicated otherwise in the credit line; if the material is not included under the Creative Commons license, users will need to obtain permission from the license holder to reproduce the material. To view a copy of this license, visit http://creativecommons.org/licenses/by/4.0/

(C) The Author(s) 2017 